\title{
Copper-palladium alloy nanoparticle plated electrodes for the electrocatalytic determination of hydrazine
}

\author{
Chih-Chio Yang ${ }^{\mathrm{a}}$, Annamalai Senthil Kumara ${ }^{\mathrm{a}}$, Ming-Chih Kuo ${ }^{\mathrm{b}}$, \\ Shu-Hua Chien ${ }^{\text {b,c }}$, Jyh-Myng Zen ${ }^{\mathrm{a}, *}$ \\ ${ }^{a}$ Department of Chemistry, National Chung Hsing University, 250 Kuo-Kuang Road, Taichung 40217, Taiwan \\ ${ }^{\mathrm{b}}$ Institute of Chemistry, Academia Sinica, Taipei 11529, Taiwan \\ ${ }^{\mathrm{c}}$ Department of Chemistry, National Taiwan University, Taipei 10664, Taiwan
}

Received 1 June 2005; received in revised form 15 July 2005; accepted 8 August 2005

Available online 5 October 2005

\begin{abstract}
The preparation of copper-palladium alloy nanoparticle plated screen-printed carbon electrodes (SPE/Cu-Pd) and their use for the electrocatalytic determination of hydrazine in $\mathrm{pH} 7.4$ phosphate buffer solution is described. X-ray photoelectron spectroscopic study indicates that the SPE/Cu-Pd prepared by successive electrochemical deposition of $\mathrm{Cu}$ and $\mathrm{Pd}$ is possessed of strong perturbed electronic interaction with a high $\mathrm{Pd} / \mathrm{Cu}$ atomic ratio. Flow injection analysis of hydrazine using the SPE/Cu-Pd shows a linear detection range of $2-100 \mu \mathrm{M}$ at an applied potential of $+0.2 \mathrm{~V}$ versus $\mathrm{Ag} / \mathrm{AgCl}$ with a current sensitivity and relative standard deviation of $0.21 \mu \mathrm{A} / \mu \mathrm{M}$ and $1.86 \%$, respectively. The detection limit $(\mathrm{S} / \mathrm{N}=3$ ) was $270 \mathrm{nM}$. Quantitative detection of hydrazine in cigarette tobacco was further demonstrated using the proposed electrode.
\end{abstract}

(C) 2005 Elsevier B.V. All rights reserved.

Keywords: Copper; Palladium; Alloy; Nanoparticle; Hydrazine; Screen-printed electrode

\section{Introduction}

Hydrazine and its derivatives are potential reducing agent anticipated to be a human carcinogen according to sufficient evidence of carcinogenicity in experimental animals [1-4]. Hydrazine is mainly used as a raw material in the manufacture of agricultural chemicals, blowing agents, polymerization catalysts as well as a propellant fuel for aircraft and spacecraft. Sensitive and selective detection of hydrazine in real sample is a challenging research in analytical chemistry. Apart from derivatization-based spectroscopic methods $[5,6]$, electroanalytical techniques were proven to be relatively direct and effective for the detection of hydrazine and its derivatives [7]. Nevertheless direct oxidation of hydrazine has been limited by a substantial overpotential $(\eta)$ at conventional carbon electrodes. One promising approach for lowering $\eta$ to facilitate the determination is through the electrocatalytic process at chemically modified electrodes [8], e.g., ruthenium or cobalt

\footnotetext{
* Corresponding author. Fax: +886 422862547.

E-mail address: jmzen@dragon.nchu.edu.tw (J.-M. Zen).
}

phthalocyanine [9-11], inorganic mixed-valent Prussian blue analogues [12-14], Nafion/lead ruthenium oxide pyrochlore [15], Nafion/ $\mathrm{Ru}^{3+}$ [16], chlorogenic acid/carbon ceramic composite [17], sweet potato tissue/paraffin graphite [18], DNA [19], carbon nanotube [20], and Pd modified electrodes [21-23]. Overall selective detection assay operated at low potentials for practical analysis is still rather limited in the literature (Table 1).

Here, we report an efficient and selective catalytic system based on a disposable copper-palladium alloy nanoparticle plated screen-printed carbon electrode (designated as $\mathrm{SPE} / \mathrm{Cu}-\mathrm{Pd}$ ) for the hydrazine oxidation reaction at a detection potential of $\sim 0 \mathrm{~V}$ versus $\mathrm{Ag} / \mathrm{AgCl}$ in neutral media. Previously copper-palladium alloy was reported to result in an improved heterogeneous catalytic behavior for variety of chemical reactions [24-33]. Nevertheless such an alloy catalytic system was seldom used in electrochemical/electrocatalytic studies. In this article, various preparation procedures were evaluated to control the catalytic property of the alloy surface. The advantages of the SPE/Cu-Pd were further explored for the detection of hydrazine by flow injection analysis (FIA). Since this FIA system is highly selective towards hydrazine, allowing thus its direct use to real samples, without any prior chromatographic 
Table 1

Literatures for electrocatalytic detection of hydrazine

\begin{tabular}{|c|c|c|c|c|}
\hline Electrode & $\mathrm{pH}$ & $E(\mathrm{~V})$ & $D_{\mathrm{L}}(\mu \mathrm{M})$ & Ref. \\
\hline 1. Dinuclear ruthenium phthalocyanine (RuPc) modified GCE & 12.0 & 0 & 0.03 & [9] \\
\hline 2. Cobalt phthalocyanine $(\mathrm{CoPc})$ modified carbon paste electrode & 13.0 & -0.1 & 100 & {$[10]$} \\
\hline 3. CoPc/cellulose acetate modified GCE & 4.7 & 0.60 & 1 & {$[11]$} \\
\hline 4. Mixed-valent $\mathrm{CoOx} /$ cyanocobaltate film electrode & 4.0 & 0.80 & 150 & [12] \\
\hline 5. Ni-hexacyanoferrate modified carbon ceramic (sol-gel) electrode & 7.0 & 0.55 & 0.24 & {$[13]$} \\
\hline 6. $\mathrm{Cu}$ - and $\mathrm{Co}-$ hexacyanoferrate modified carbon fiber microelectrode (potentiometric sensor) & 7.0 & - & 0.50 & {$[14]$} \\
\hline 7. Nafion/lead ruthenium oxide pyrochlore modified GCE & 7.0 & 0.70 & 0.15 & {$[15]$} \\
\hline 8. Nafion/ $/ \mathrm{Ru}^{3+}$ modified GCE & 1.0 & 1.0 & 0.1 & {$[16]$} \\
\hline 9. Chlorogenic acid/carbon ceramic composite electrode & 8.0 & 0.25 & 20 & [17] \\
\hline 10. Paraffin/graphite modified with a sweet potato tissue electrode (biosensor) & 7.0 & -0.22 & 0.5 & {$[18]$} \\
\hline 11. DNA modified SPE & 5.0 & 0.50 & - & [19] \\
\hline 12. Carbon nanotube modified microelectrode & 7.0 & 0.50 & 1.0 & {$[20]$} \\
\hline 13. Pd/CNT/4-aminobenzene monolayer grafted GCE & 4.0 & 0.40 & 1.0 & {$[21]$} \\
\hline 14. Pd modified carbon fiber microdisk array electrode & 5.5 & 0.50 & 1.0 & {$[22]$} \\
\hline 15. Pd modified electrochemical detector for capillary electrophoresis system & 7.3 & 0.50 & 1.5 & {$[23]$} \\
\hline 16. $\mathrm{Cu}-\mathrm{Pd}$ alloy nanoparticle modified SPE & 7.0 & 0.20 & 0.27 & This work \\
\hline
\end{tabular}

separation. It has been successfully demonstrated for the determination of hydrazine in cigarette tobacco.

\section{Experimental}

\subsection{Reagents}

Standard solutions of $\mathrm{Cu}(\mathrm{II})$ and $\mathrm{Pd}(\mathrm{II})(1000 \mathrm{mg} / \mathrm{l}$, AAS grade) were bought from Merck. Standard hydrazine solution, 98\% (19.57 M), was purchased from Lancaster. The $200 \mathrm{ppm}$ $\mathrm{Cu}$ (II) and $100 \mathrm{ppm} \mathrm{Pd}(\mathrm{II})$ solutions in $0.05 \mathrm{M} \mathrm{HNO}_{3}$ were used for platting experiments. Unless otherwise mentioned, a pH 7.4 phosphate buffer solution (PBS, $I=0.1 \mathrm{M}$ ) was used as supporting electrolyte. All compounds (ACS-certified reagent grade) were used without further purification. Aqueous solutions were prepared with doubly distilled and deionized water.

\subsection{Apparatus}

Cyclic voltammetric experiments were carried out with a BAS CV-50W electrochemical analyzer (West Lafayette, IN, USA). The three-electrode system consists of a SPE working electrode with a geometric area of $0.07 \mathrm{~cm}^{2}$ (Zensor R\&D, Taiwan), an $\mathrm{Ag} / \mathrm{AgCl}$ reference (Model RE-5, BAS), and a platinum auxiliary electrode. The SPE's resistance was measured as $145.3 \pm 5.7 \Omega / \mathrm{cm}$ using a two-point probe digital multimeter. Hydrodynamic amperometric measurements were performed using a CHI 1221 electrochemical workstation (Austin, TX, USA). The FIA system consisted of a Cole-Parmer microprocessor pump drive, a Rehodyne model 7125 sample injection valve (20 $\mu$ l loop) with interconnecting Teflon tube and a Zensor SF100 thin-layer electrochemical cell (Zensor R\&D, Taiwan).

$\mathrm{X}$-ray photoelectron spectroscopic (XPS) analysis (Omicron DAR 400, Germany) was performed by using an Al K $\alpha$ X-ray radiation source $(1486.6 \mathrm{eV})$ with $0.1 \mathrm{eV}$ of resolution. The pressure inside the analyzer was maintained at $\sim 10^{-10}$ Torr during the measurement. Prior to the experiment, the binding energy (BE) was standardized with $\mathrm{Au} 4 \mathrm{f}_{3 / 2}(84.0 \mathrm{eV}$, fwhm $=1.20 \mathrm{eV})$.
The $\mathrm{C} 1 \mathrm{~s}$ peak at $284.6 \mathrm{eV}$ was taken uniformly as an internal standard. The high-resolution spectra were performed under ambient conditions and averaged by number of scans to increase the signal-to-noise ratio. Quantitative XPS analysis was carried out by using an Origin 6.0 graphic program to pick up the intensity maximum and BE values. XPS peak areas were calculated using in-built software programs. Peak sensitive parameters were used to calculate the atomic ratios.

\subsection{Electrode preparation}

For the preparation of copper nanoparticle plated SPE $(\mathrm{SPE} / \mathrm{Cu})$, a clean SPE was electrochemically treated in $200 \mathrm{mg} / \mathrm{l}$ $\mathrm{Cu}$ (II) standard solution at an applied potential of $-0.7 \mathrm{~V}$ versus $\mathrm{Ag} / \mathrm{AgCl}$ for $300 \mathrm{~s}$. Similarly, for the case of palladium nanoparticles plated SPE (SPE/Pd), we used $100 \mathrm{mg} / \mathrm{l} \mathrm{Pd(II)} \mathrm{standard}$ solution at $-0.6 \mathrm{~V}$ versus $\mathrm{Ag} / \mathrm{AgCl}$ for $180 \mathrm{~s}$. The optimized plating time ranging from 30 to $300 \mathrm{~s}$ was chosen based on experimental requirement in the presence of 10,100 , and $200 \mathrm{ppm}$ of $\mathrm{Cu}$ (II) or $\mathrm{Pd}(\mathrm{II})$ solution. The $\mathrm{SPE} / \mathrm{Cu}-\mathrm{Pd}$ was prepared by a successive plating procedure in which first $\mathrm{Cu}$ layer and then $\mathrm{Pd}$ overlayer on the SPE. The SPE/Pd-Cu was prepared in a similar way, except with first $\mathrm{Pd}$ and then $\mathrm{Cu}$ layers. A co-deposition method was adopted for the case of SPE/Cu + Pd, where $\mathrm{Cu}(\mathrm{II})$ and $\mathrm{Pd}(\mathrm{II})$ mixture solution was used for electroplating at $-0.7 \mathrm{~V}$ versus $\mathrm{Ag} / \mathrm{AgCl}$ for $180 \mathrm{~s}$. All further analytical studies were done with the $\mathrm{SPE} / \mathrm{Cu}-\mathrm{Pd}$ as it showed the best electrocatalytic result to the detection of hydrazine.

\subsection{Procedure}

The SPE/Cu-Pd was first washed thoroughly with deionized water, and then pretreated by continuously scanning at $20 \mathrm{mV} / \mathrm{s}$ in $0.1 \mathrm{M}$ PBS in the window of 0.4 to $-0.6 \mathrm{~V}$ until a stable background current was obtained. As to FIA, the SPE/Cu-Pd was equilibrated in blank PBS at a suitable potential until the current became constant. The quantification of hydrazine was achieved by measuring the oxidation current from a current-time 
$(i-t)$ curve. All experiments were performed at room temperature $\left(25^{\circ} \mathrm{C}\right)$.

Three famous brand cigarettes were purchased from a local supermarket and used for real sample analysis without any pretreatment. Real sample was prepared by first removing the tobacco content from the cigarette. It was weighted and dissolved in $0.1 \mathrm{M}$, pH 7.4 PBS followed by $5 \mathrm{~min}$ of ultrasonification. The filtrated solution was then suitably diluted for the real sample analysis.

\section{Results and discussion}

\subsection{Electrocatalytic behavior of the $S P E / C u-P d$}

Cyclic voltammetric responses of hydrazine at various electrodes of SPE/Cu, SPE/Pd, SPE/Cu + Pd, SPE/Pd-Cu, and $\mathrm{SPE} / \mathrm{Cu}-\mathrm{Pd}$ were first studied and compared. As shown in Fig. 1, profound reduction peaks at $-0.2 \mathrm{~V}(\mathrm{C} 2)$ and $-0.3 \mathrm{~V}$ (C1) corresponding to the reduction of $\mathrm{CuO} \rightarrow \mathrm{Cu}_{2} \mathrm{O}$ and $\mathrm{Cu}_{2} \mathrm{O} \rightarrow \mathrm{Cu}$, respectively, in the cathodic scan were observed at the $\mathrm{SPE} / \mathrm{Cu}$; while a shoulder at $\sim 0.0 \mathrm{~V}$ corresponding to the oxidation of $\mathrm{CuO}$ and $\mathrm{Cu}_{2} \mathrm{O}$ (A2 and $\left.\mathrm{A} 1\right)$ was obtained in the reverse step [34,35]. No electrocatalytic behavior towards the oxidation of hydrazine was detected on the SPE/Cu. As to the case of SPE/Pd, two distinctive current responses at around -0.3 to -0.6 and $+0.2 \mathrm{~V}$ presumably due to hydrogen adsorption-desorption $\left(H_{\mathrm{a}} / H_{\mathrm{c}}\right)$ and palladium oxide reduction, respectively, were observed (Fig. 1B) [36,37]. The SPE/Pd shows a marked oxidative current response at the $H_{\mathrm{a}} / H_{\mathrm{c}}$ region in the presence of hydrazine. Nevertheless such an oxidative behavior was not stable with a continuously decrease in current upon repeated cycles (ca. decrease by $\sim 30 \%$ upon 20 cycles). The SPE/Pd-Cu, on the other hand, shows a similar electrochemical result to that of SPE/Cu. Obviously, the outer $\mathrm{Cu}$ surface can resist further hydrazine oxidation and the result is therefore similar to the case of SPE/Cu. The $\mathrm{SPE} / \mathrm{Cu}+\mathrm{Pd}$ also did not perform very well with a behavior similar to that of the SPE/Pd. It is interesting to observe a stable catalytic response at $\sim 0.0 \mathrm{~V}$ upon repeated cycles $(n=20)$ at the SPE/Cu-Pd. Unlike the interfacial interaction observed on the SPE/Pd-Cu, the alloy formation should be the key for such a performance. In order to quantitatively compare the catalytic efficiency, hydrazine oxidation current at $0.0 \mathrm{~V}$ was calculated as catalytic current function $\left(i_{\mathrm{f}}^{\mathrm{cat}}\right)$. As shown in Fig. $1 \mathrm{~F}$, the catalytic response was observed to be in the order of $\mathrm{SPE} / \mathrm{Cu}<\mathrm{SPE} / \mathrm{Pd}-\mathrm{Cu}<\mathrm{SPE} / \mathrm{Cu}+\mathrm{Pd} \approx \mathrm{SPE} / \mathrm{Pd} \ll \mathrm{SPE} / \mathrm{Cu}-\mathrm{Pd}$.
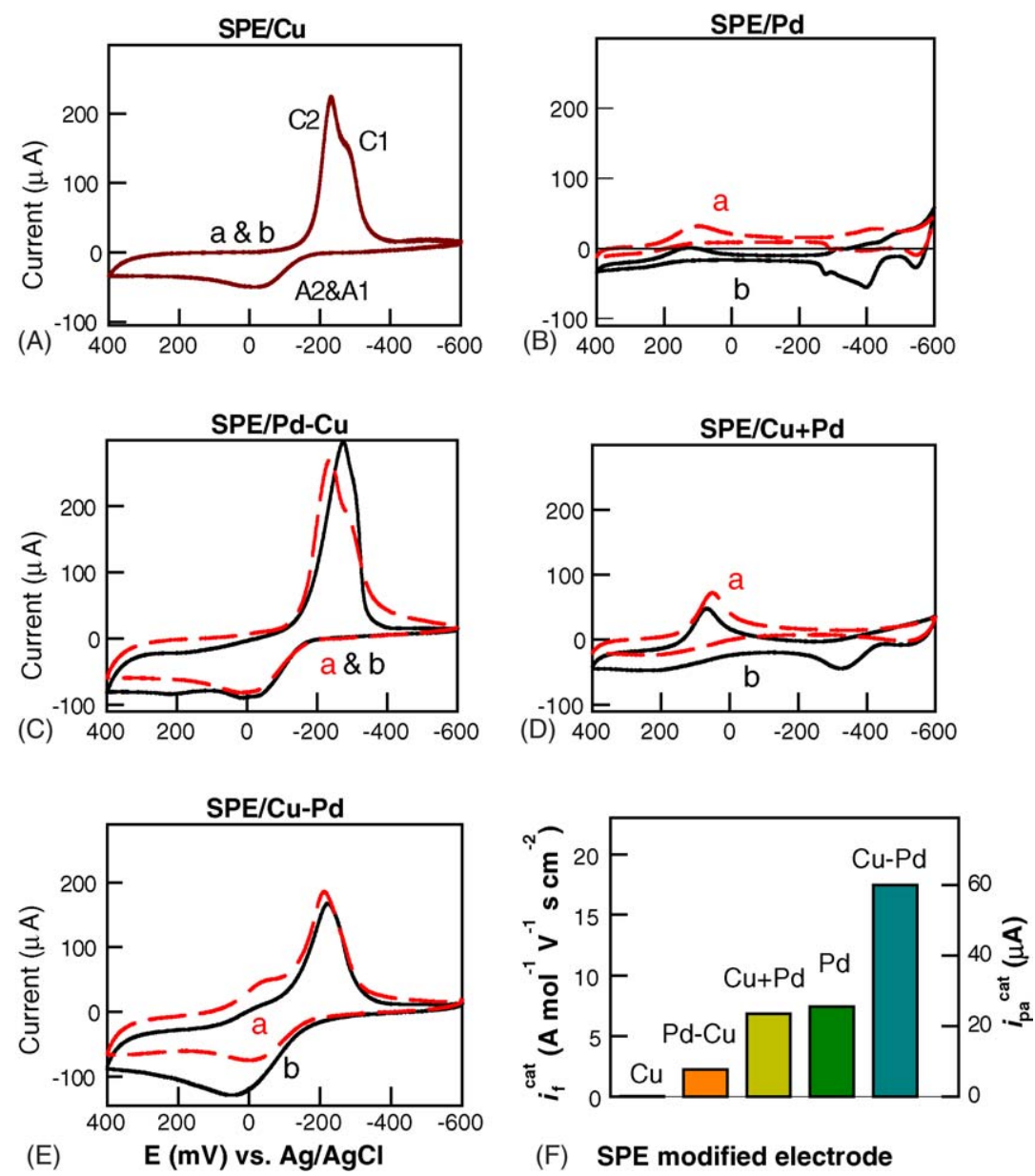

Fig. 1. (A-E) Cyclic voltammetric responses of various SPEs in the absence (a) and presence (b) of $1 \mathrm{mM}$ hydrazine at a scan rate of $50 \mathrm{mV} / \mathrm{s}$ in $\mathrm{pH} 7.4 \mathrm{PBS}$. (F) Plots of catalytic current function $\left(i_{\mathrm{f}}^{\text {cat }}\right)$ and catalytic peak current $\left(i_{\mathrm{pa}}^{\text {cat }}\right)$ for different SPEs. The oxidation and reduction corresponds to downward and upward current responses, respectively. 
(A)
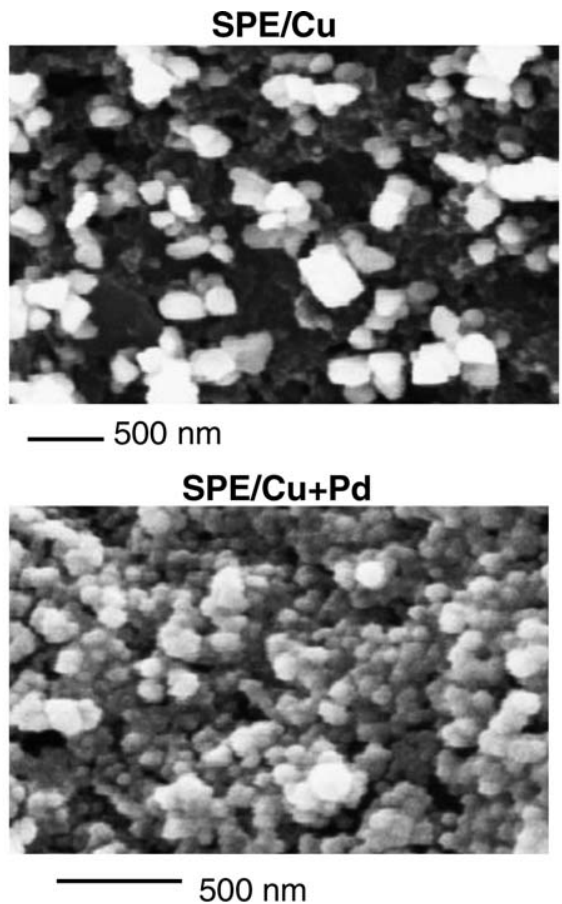

(B)
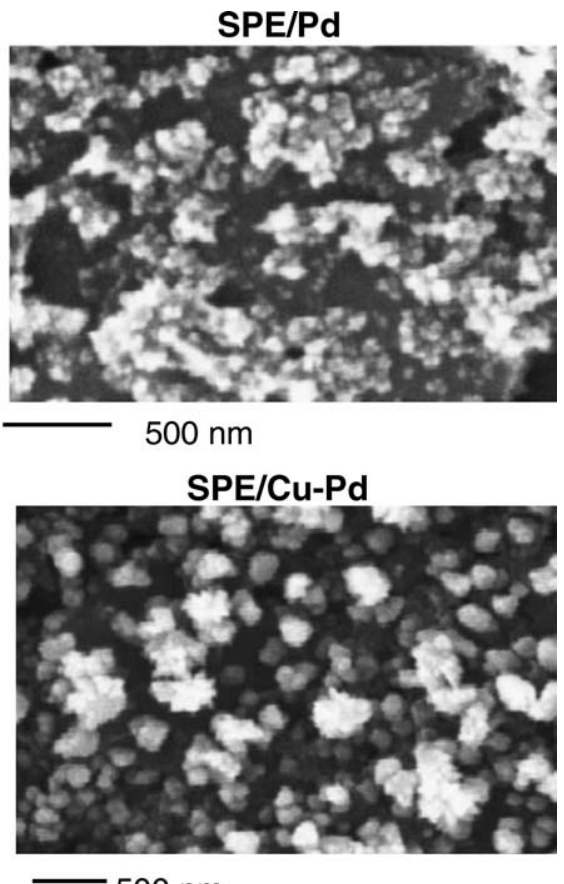

(D)

Fig. 2. Scanning electron microscopic surface morphological pictures of SPE/Cu (A), SPE/Pd (B), SPE/Cu + Pd (C), and SPE/Cu-Pd (D)

Overall the nature of electrode prepared is essential to control the catalytic feature.

Further experiments with increasing in scan rate $(v)$ for the electrocatalytic oxidation of hydrazine on the SPE/Cu-Pd were studied. The catalytic current $\left(i_{\mathrm{pa}}^{\mathrm{cat}}\right)$ was found to systematically increase with $v$. A plot of $\log \left(i_{\mathrm{pa}}^{\mathrm{cat}}\right)$ versus $\log (v)$ yielded a straight line up to $100 \mathrm{mV} / \mathrm{s}$ with a slope (i.e., $\partial \log \left(i_{\mathrm{pa}}^{\text {cat }}\right) / \partial \log (v)$ ) of $\sim 0.5$, indicating a diffusion-controlled electron transfer mechanism for the hydrazine oxidation reaction at the SPE/Cu-Pd. The fact that no hydrazine peak was observed in blank electrolyte after a medium exchange process further supported the absence of adsorption on the SPE/Cu-Pd. Based on $\mathrm{d} E_{\mathrm{pa}} / \mathrm{d} \log (v)=b_{\mathrm{a}} / 2$, from the plot of $E_{\mathrm{pa}}$ versus $\log (v)$, a Tafel slope $\left(b_{\mathrm{a}}\right)$ of $97.5 \mathrm{mV} /$ decade was obtained [38,39]. Assuming one-electron transfer in the rate-determining step $\left(n_{\mathrm{a}}=1\right)$, the anodic transfer coefficient $\left(\alpha_{\mathrm{a}}\right)$ was calculated as 0.62 according to the equation of $b_{\mathrm{a}}=2.303 R T / n_{\mathrm{a}} F \alpha_{\mathrm{a}}$. In other words, the energy barrier for the hydrazine oxidation is nonsymmetric and favorable to the anodic oxidation side.

\subsection{Surface characterization}

Fig. 2 shows surface morphological view of the $\mathrm{Cu}, \mathrm{Pd}$, $\mathrm{Cu}+\mathrm{Pd}$, and $\mathrm{Cu}-\mathrm{Pd}$ films on the SPE. As can be seen, the particle size is relatively bigger at the $\mathrm{SPE} / \mathrm{Cu}(\sim 100 \mathrm{~nm})$ than that at the SPE/Pd $(\sim 50 \mathrm{~nm})$. The SPE/Cu $+\mathrm{Pd}$, on the other hand, possesses continuous and fine nanoparticle clusters $(\sim 50 \mathrm{~nm})$ with a relatively higher surface particle density than that at the $\mathrm{SPE} / \mathrm{Pd}$. This observation seems to correlate well with the similar electrocatalytic behavior between $\mathrm{SPE} / \mathrm{Cu}+\mathrm{Pd}$ and $\mathrm{SPE} / \mathrm{Pd}$ as reported earlier. It is interesting to observe a similar surface morphology between SPE/Cu-Pd and SPE/Cu and the fine metal/metal alloy nanoparticle formation on the SPE surface is obvious.

Further XPS study helps to characterize the $\mathrm{Cu}-\mathrm{Pd}$ alloy's surface. Fig. 3 shows high-resolution XPS spectra of $\mathrm{Cu} 2 \mathrm{p}, \mathrm{Pd}$ $3 \mathrm{~d}$, and $\mathrm{O} 1 \mathrm{~s}$ core energy levels for various electrodes. Oxide forms (O 1s: 532.1 and $533.5 \mathrm{eV}$ ) predominantly as $\mathrm{Cu}_{2} \mathrm{O} / \mathrm{Cu}$ species $(933.1 \mathrm{eV})$ with minor $\mathrm{CuO}(934.5 \mathrm{eV})$ was observed on the SPE/Cu $[40,41]$. As to the SPE/Pd, both $\mathrm{Pd}$ and $\mathrm{PdO}$ were identified on the surface based on the $\mathrm{Pd} 3 \mathrm{~d}_{5 / 2} \mathrm{BE}$ values of 335.3 and $336.4 \mathrm{eV}$ [37]. The core energy responses of $\mathrm{Cu}$ $2 \mathrm{p}, \mathrm{Pd} 3 \mathrm{~d}$, and $\mathrm{O} 1 \mathrm{~s}$ were qualitatively similar in $\mathrm{SPE} / \mathrm{Cu}+\mathrm{Pd}$, $\mathrm{SPE} / \mathrm{Pd}-\mathrm{Cu}$, and SPE/Cu-Pd. The BE level of $\mathrm{Cu} 2 \mathrm{p}_{3 / 2}$ is most valuable as it is keen and sensitive to the $\mathrm{Cu}-\mathrm{Pd}$ alloy formation as well as its dimension. By taking $\mathrm{SPE} / \mathrm{Cu}$ as a reference level, the calculated $\mathrm{BE}$ shift values are $-0.6,0$, and $-0.7 \mathrm{eV}$ for $\mathrm{SPE} / \mathrm{Cu}+\mathrm{Pd}, \mathrm{SPE} / \mathrm{Pd}-\mathrm{Cu}$, and $\mathrm{SPE} / \mathrm{Cu}-\mathrm{Pd}$, respectively. As reported earlier, the negative shift in the $\mathrm{BE}$ level of $\mathrm{Cu} 2 \mathrm{p}_{3 / 2}$ is related to the perturbed electronic interaction between $\mathrm{Cu}$ and $\mathrm{Pd}$ atomic orbital and in turn to its alloy formation $[42,43]$. The $\mathrm{Cu}-\mathrm{Pd}$ alloy prepared under a high temperature annealing process can yield up to $-0.97 \mathrm{eV}$ of $\mathrm{BE}$ shit in the $\mathrm{Cu} 2 \mathrm{p}_{3 / 2}$ core energy level [43]. The SPE/Cu-Pd, with a $-0.7 \mathrm{eV}$ shift value, is thus possessed of a more effective coordination between $\mathrm{Cu}-\mathrm{Pd}$ than those of $\mathrm{Pd}-\mathrm{Cu}$ and $\mathrm{Cu}+\mathrm{Pd}$ systems. This is also the main reason why only the SPE/Cu-Pd shows an enhanced electrocatalytic hydrazine oxidation current response as illustrated in Fig. 1.

Table 2 summarizes the atomic ratio values calculated from the XPS peak parameters. The $\mathrm{Pd} / \mathrm{Cu}$ atomic ratio is 0.52 , 0.38 , and 0.007 for SPE/Cu-Pd, SPE/Cu + Pd, and SPE/Pd-Cu, respectively. Note that, based on the plating concentration the calculated $\mathrm{Pd} / \mathrm{Cu}$ atomic ratio is 0.44 , which is close to the 

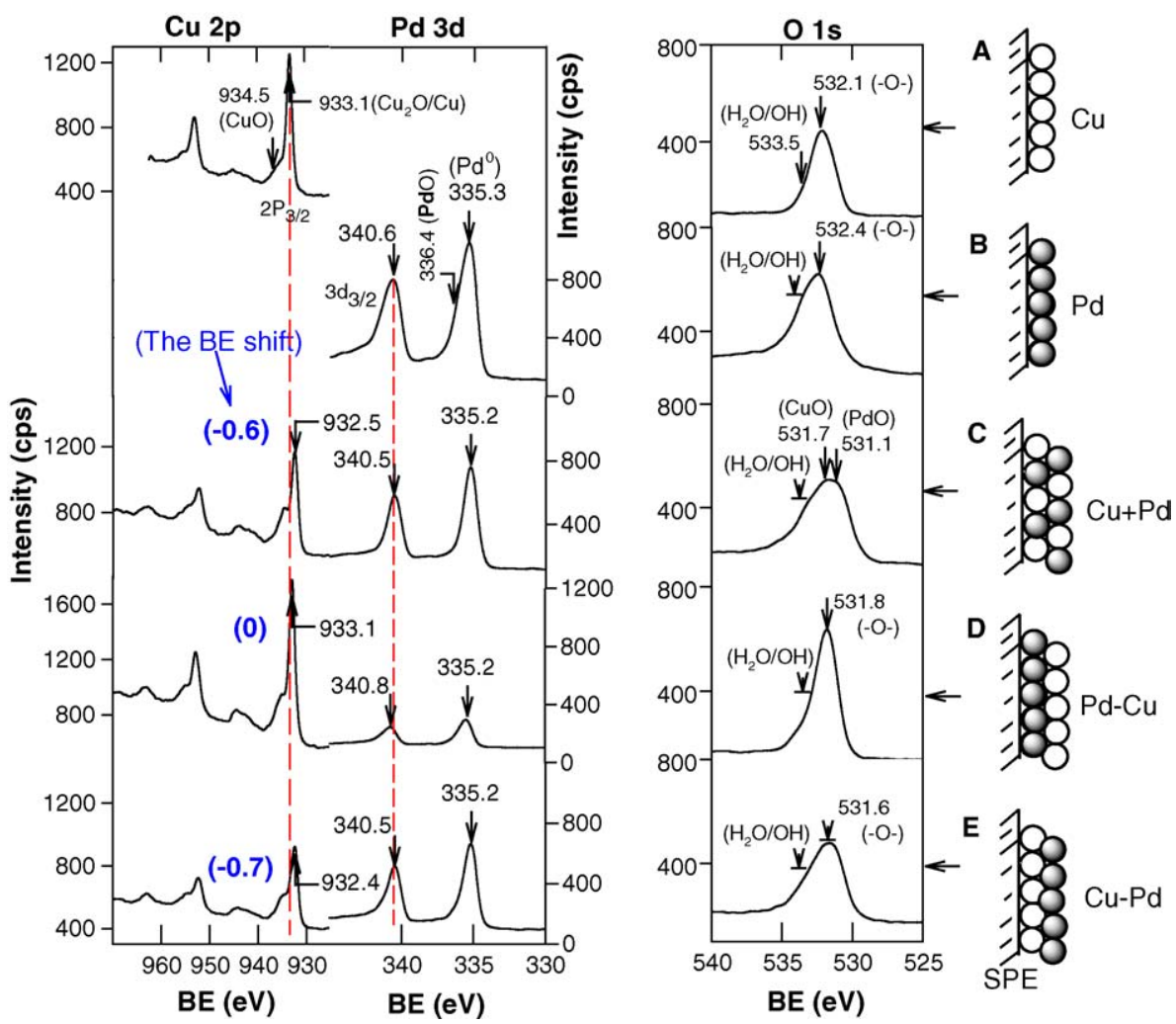

Fig. 3. High-resolution X-ray photoelectron spectroscopic results of $\mathrm{Cu} 2 \mathrm{p}, \mathrm{Pd} 3 \mathrm{~d}$, and O 1s core-energy levels of various SPEs.

Table 2

Atomic ratio parameters for different electrodes

\begin{tabular}{|c|c|c|c|c|c|}
\hline Atomic ratio & $\mathrm{SPE} / \mathrm{Cu}$ & $\mathrm{SPE} / \mathrm{Pd}$ & $\mathrm{SPE} / \mathrm{Cu}+\mathrm{Pd}$ & $\mathrm{SPE} / \mathrm{Pd}-\mathrm{Cu}$ & $\mathrm{SPE} / \mathrm{Cu}-\mathrm{Pd}$ \\
\hline$N_{\mathrm{O} 1 \mathrm{~s}} / N_{\mathrm{Cu} 2 \mathrm{p}_{3 / 2}}$ & 1.59 & - & 2.56 & 1.46 & 2.38 \\
\hline$N_{\mathrm{O} 1 \mathrm{~s}} / N_{\mathrm{Pd} 3 \mathrm{~d}_{5 / 2}}$ & - & 3.87 & 6.67 & 19.56 & 4.59 \\
\hline
\end{tabular}

observed value of $0.38\left(N_{\mathrm{Pd} 3 \mathrm{~d}_{5 / 2}} / N_{\mathrm{Cu} 2 \mathrm{p}_{3 / 2}}\right)$ for the $\mathrm{SPE} / \mathrm{Cu}+\mathrm{Pd}$. Most important of all, the atomic ratios are in parallel with the shift in the BE values. The SPE/Cu-Pd with the highest $\mathrm{Pd} / \mathrm{Cu}$ atomic ratio also shows the best electrocatalytic response. Meanwhile a much higher $N_{\mathrm{O} 1 \mathrm{~s}} / N_{\mathrm{Pd}_{3 d_{5 / 2}}}$ atomic ratio of 19.56 for the SPE/Pd-Cu than that of 4.59 for the SPE/Cu-Pd indicates the oxide layer may hinder the alloy formation and in turn to the catalytic performance. The advantage of the SPE/Cu-Pd is then used for the hydrazine quantification by flow injection analysis.

\subsection{Analytical applications}

Initial experiments were focused on the optimization of the hydrodynamic parameters, flow rate $\left(H_{\mathrm{f}}\right)$ and applied potential $\left(E_{\mathrm{app}}\right)$, on the detection of $50 \mu \mathrm{M}$ hydrazine using $0.1 \mathrm{M}$, $\mathrm{pH} 7.4$ PBS carrier solution. As can be seen in Fig. 4, the peak currents were systematically increased with the increase in $H_{\mathrm{f}}$ up to $900 \mu \mathrm{l} / \mathrm{min}$; after that a plateau in the response was obtained. The detection signal at $H_{\mathrm{f}}=900 \mu \mathrm{l} / \mathrm{min}$ is about twice higher than that at $H_{\mathrm{f}}=200 \mu \mathrm{l} / \mathrm{min}$. This is due to the diffusioncontrolled electron transfer characteristics of the hydrazine oxidation as discussed earlier. To save the waste of carrier buffer,
$H_{\mathrm{f}}=500 \mu \mathrm{l} / \mathrm{min}$ was chosen to study the influence of $E_{\mathrm{app}}$. In the potential window of 0.3 to $-0.3 \mathrm{~V}$ versus $\mathrm{Ag} / \mathrm{AgCl}$, almost no alteration in the FIA signals was observed up to $0.0 \mathrm{~V}$ with a steep decrease in the detection response after that (data not enclosed). The observation is indeed in good agreement with the electrocatalytic responses observed by $\mathrm{CV}$ as shown in Fig. 1E.

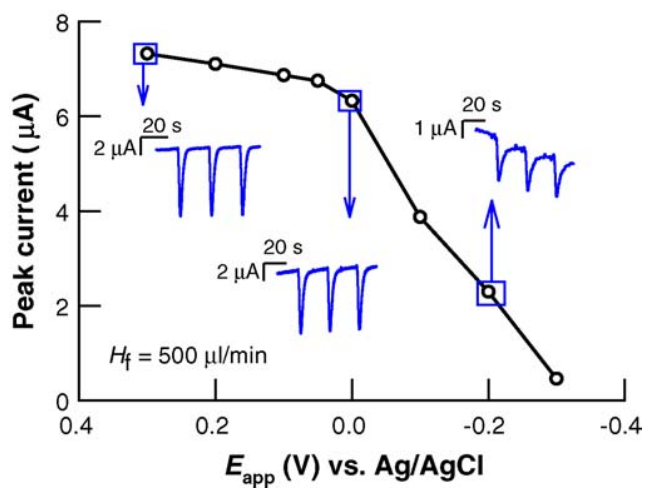

Fig. 4. Plot of FIA peak current vs. hydrodynamic flow rate, $H_{\mathrm{f}}\left(E_{\mathrm{app}}=0.2 \mathrm{~V}\right.$ vs. $\mathrm{Ag} / \mathrm{AgCl}$ ) for the detection of $50 \mu \mathrm{M}$ hydrazine using the $\mathrm{SPE} / \mathrm{Cu}-\mathrm{Pd}$ in $\mathrm{pH}$ 7.4 PBS carrier solution. 


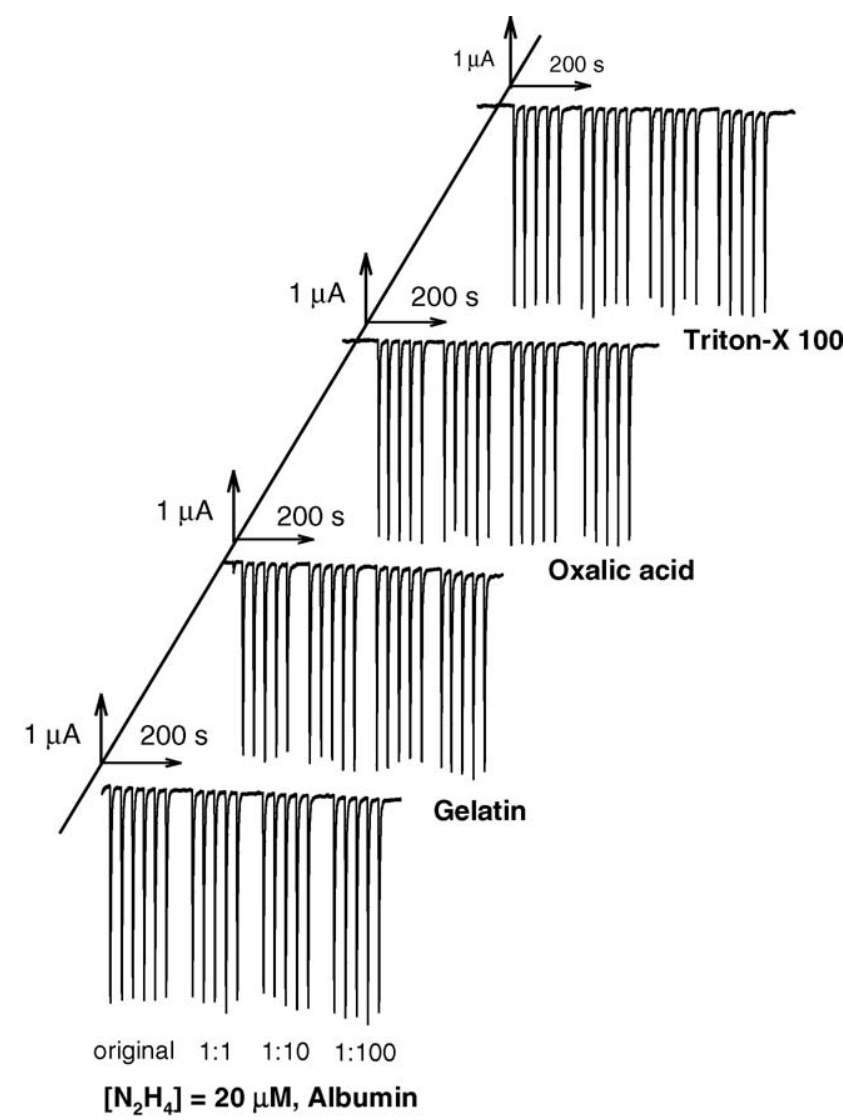

Fig. 5. FIA detection of $20 \mu \mathrm{M}$ hydrazine with/without albumin, gelatin, oxalic acid, and Triton X-100 at different ratios. $E_{\text {app }}=0.2 \mathrm{~V}$ vs. $\mathrm{Ag} / \mathrm{AgCl}$ and $H_{\mathrm{f}}=500 \mu \mathrm{l} / \mathrm{min}$ at the SPE/Cu-Pd in pH.7.4 PBS carrier buffer solution.

Continuous hydrazine injection yielded a very stable baseline response at $E_{\text {app }}=+0.2 \mathrm{~V}$. This detection potential was thus used in all further experiments.

Fig. 5 shows the typical FIA hydrazine signals with a linear increase in FIA responses in the window of $2-100 \mu \mathrm{M}$. The calculated sensitivity and regression coefficient were $0.21 \mu \mathrm{A} / \mu \mathrm{M}$ and 0.999 , respectively. Repeated injection of $2 \mu \mathrm{M}$ hydrazine yielded a R.S.D. of only $1.86 \%(n=11)$ indicating good reproducibility of the working electrode. The detection limit $\left(D_{\mathrm{L}}, \mathrm{S} / \mathrm{N}=3\right)$ was $270 \mathrm{nM}$. Note that both the electrode detection parameters and analytical conditions were better than those of Co-phthalocyanine/cellulose acetate [11], nickel hexacyanoferrate/sol-gel [13], DNA [19], CNT [20], and Pd modified systems [21-23].

The effect of potential interferents on the hydrazine amperometric response was checked under optimized FIA conditions. Interference effect was studied by detecting $20 \mu \mathrm{M}$ hydrazine with $10 \times$ and $100 \times$ excess in concentration of albumin, gelatine, oxalic acid, and Triton X-100 (Fig. 5). The purpose is to investigate the electrode durability and selectivity towards various practical systems from biological, environmental, and industrial samples. The compounds checked were selected as they were often reported to cause a surface fouling effect to the detection of hydrazine $[10,11,15]$. For example, both the CoPc and CoPc/cellulose acetate modified GCEs were reported to have a marked peak current loss in the presence of gelatin in FIA

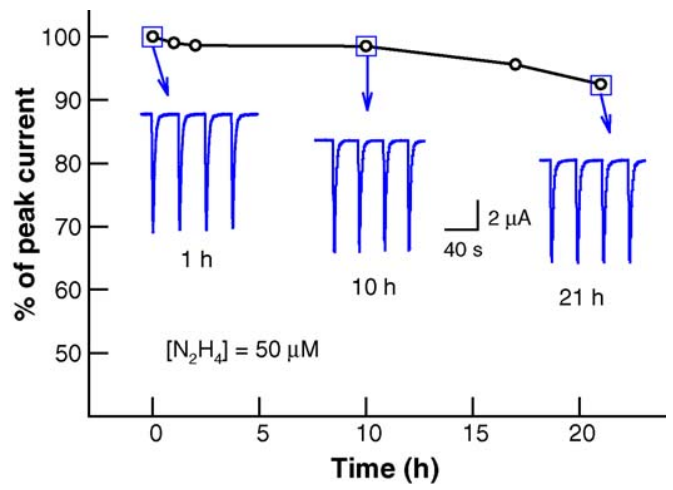

Fig. 6. FIA response for the oxidation of $50 \mu \mathrm{M}$ of hydrazine at SPE/Cu-Pd with different time intervals. Other conditions are similar to those in Fig.5.

$[10,11]$. This is also true for most metal hexacyanoferrate modified systems. The Nafion/ $\mathrm{Ru}^{3+}$ modified GCE showed $\sim 20 \%$ alteration in the hydrazine signal in the presence of $50 \mu \mathrm{M}$ of oxalic acid and albumin at $E_{\text {app }}=1.0 \mathrm{~V}$ versus $\mathrm{Ag} / \mathrm{AgCl}$ [16]. As shown in Fig. 5, the SPE/Cu-Pd shows almost no alteration in the FIA signals with/without the addition of these interferents. It can prevent the interference for even up to a 1:100 ratio. Of course, the low detection potential is a clear advantage for the elimination of the interference in this study. Long-term stability of the SPE/Cu-Pd was also studied by testing the electrode at $+0.2 \mathrm{~V}$ under constant flow of the carrier buffer solution. As can be seen in Fig. 6, the SPE/Cu-Pd yielded $\sim 5 \%$ loss in peak current after $21 \mathrm{~h}$ of continuous run without any marked foul-off characteristics. All these results indicate the applicability of the $\mathrm{SPE} / \mathrm{Cu}-\mathrm{Pd}$ for practical analysis.

Finally, selective detection of hydrazine in cigarette tobacco is presented in this study as an example of real sample analysis. Hydrazine and derivatives was reported to contain $4-10 \%$ of its content from tobacco (originated from agricultural chemicals) into mainstream smoke $[44,45]$. The experimental procedure is simply by injecting the diluted cigarette tobacco solution directly into the carrier solution for detection. Fig. 7 shows typical hydrazine real sample assays for three famous brands of cigarette (\#1-\#3) using the SPE/Cu-Pd by standard addition method. Note that all three assays were carried out using a same strip of SPE/Cu-Pd. Table 3 summarizes the results obtained with the amount of hydrazine detected in the range of $186.2-528.6 \mathrm{ng} /$ cigarette. The detected

Table 3

Hydrazine assay in cigarette tobacco sample solutions using the SPE/Cu-Pd

\begin{tabular}{llll}
\hline Parameters & Cigarette \#1 & Cigarette \#2 & Cigarette \#3 \\
\hline Tobacco weight $(\mathrm{g})$ & 0.801 & 0.750 & 0.751 \\
Diluted volume $(\mathrm{ml})$ & 1000 & 200 & 1000 \\
Linear equation & $y=0.148 x+$ & $y=0.079 x+$ & $y=0.138 x+$ \\
& 0.988 & 1.97 & 1.93 \\
$R$ & 0.998 & 0.995 & 0.991 \\
Detect value $(\mu \mathrm{M})$ & 6.72 & 24.8 & 14.06 \\
Spike $(\mu \mathrm{M})$ & 10 & 10 & 10 \\
After spike $(\mu \mathrm{M})$ & 16.77 & 34.36 & 24.32 \\
Recovery $(\%)$ & 100.74 & 95.6 & 102.6 \\
Hydrazine $(\mathrm{ng} /$ cigarette) & $269.4 \pm 5.4$ & $186.2 \pm 4.0$ & $528.6 \pm 9.4$ \\
\hline
\end{tabular}




\section{(A) Cigarette \#1}

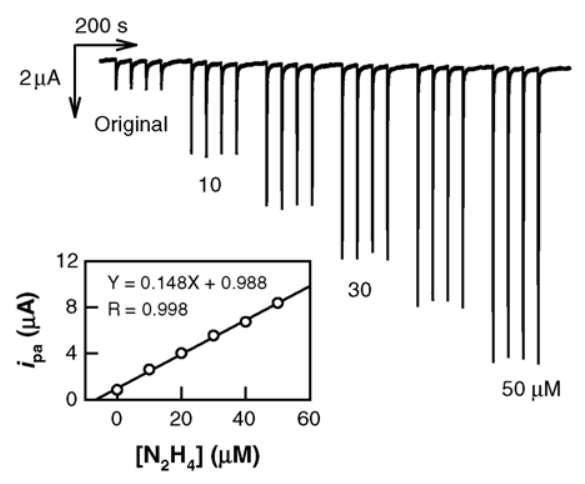

(B) Cigarette \#2

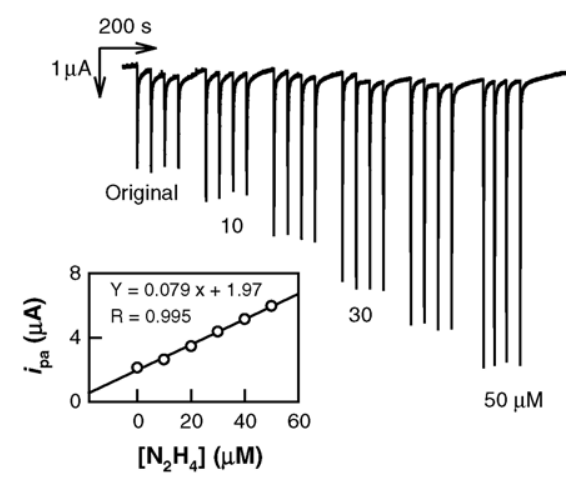

(C) Cigarette \#3

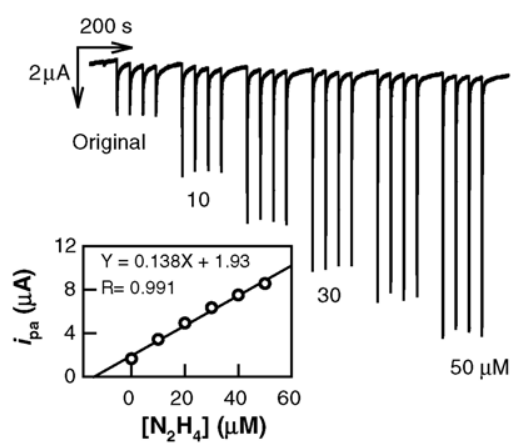

Fig. 7. Real sample analysis for the detection of hydrazine in cigarette tobacco. Other FIA conditions are similar to those in Fig. 5.

value of $186.2 \mathrm{ng} /$ cigarette is close to the measured value of $188.1 \mathrm{ng} /$ cigarette using a barrel plating rhodium electrode from our previous report for a same brand of cigarette [46]. Of course, further detailed real sample analysis to various tobacco containing products in parallel with a standard hydrazine detection method is necessary for the results of accuracy. Cyclic voltammograms of the SPE/Cu-Pd before and after real samples also did not show any marked alteration in the current and potential values in blank base electrolyte solution, indicating good reproducibility of the working electrodes. The recoveries for all three samples all fall in the window of $95.6-103.2 \%$ verify that the proposed system is suitable for the determination of hydrazine in real samples.

\section{Conclusions}

The SPE/Cu-Pd prepared under successive electrochemical deposition of $\mathrm{Cu}$ and Pd showed an enhanced hydrazine electrocatalytic response under low detection potentials in neutral media. Strong perturbed electronic interaction between the $\mathrm{Cu}$ and Pd atomic orbital with an increased alloy formation is specifically with the SPE/Cu-Pd. Stable electrocatalytic response was noticed without any adsorption-related complication on the SPE/Cu-Pd. The electrode possesses good sensitivity with a detection limit down to nano-molar range by flow injection analysis. The SPE/Cu-Pd is free from interference of albumin, gelatin, oxalic acid, and Triton X-100 up to a high concentration of $2 \mathrm{mM}$. The real sample assay for the detection of hydrazine in cigarette tobacco is promising. The cheap $\mathrm{SPE} / \mathrm{Cu}-\mathrm{Pd}$ system can be extendable to variety of application with a portable design. Further work is in progress in this laboratory.

\section{Acknowledgment}

The authors gratefully acknowledge financial support from the National Science Council of Taiwan.

\section{References}

[1] K. Walton, M.M. Coombs, L.J. King, R. Walker, C. Ioannides, Nutr. Cancer 37 (2000) 55.

[2] H. Zheng, R.C. Shank, Carcinogenesis 17 (1996) 2711.

[3] T. Leakakos, R.C. Shank, Toxicol. Appl. Pharmacol. 126 (1994) 295.

[4] WHO, EHC No. 68: Hydrazine, World Health Organization, Geneva, 1987.

[5] C.X. Gao, T.Y. Chou, S.T. Colgan, I.S. Krull, C. Dorschel, B. Bidlingmeyer, J. Chromatogr. Sci. 26 (1988) 449.

[6] A. Safavi, M.A. Arimi, Talanta 58 (2002) 785.

[7] K. Ravichandran, R.P. Baldwin, Anal. Chem. 55 (1983) 1782

[8] J.-M. Zen, A.S. Kumar, D.-M. Tsai, Electroanalysis 15 (2003) 1073.

[9] M. Ebadi, Can. J. Chem. 81 (2003) 161.

[10] K.M. Korfhage, K. Ravichandran, R.P. Baldwin, Anal. Chem. 56 (1984) 1514.

[11] J. Wang, T. Golden, R. Li, Anal. Chem. 60 (1988) 1642.

[12] J. Zhou, E. Wang, Talanta 40 (1993) 943.

[13] A. Salimi, K. Abdi, Talanta 63 (2004) 475 
[14] J.-W. Mo, B. Ogorevc, X. Zhang, B. Pihlar, Electroanalysis 12 (2000) 48.

[15] J.-M. Zen, J.-S. Tang, Anal. Chem. 67 (1995) 208.

[16] I.G. Casella, M.R. Guascito, A.M. Selvi, E. Desimoni, Anal. Chim. Acta 354 (1997) 333.

[17] A. Salimi, R. Hallaj, Electroanalysis 16 (2004) 1964.

[18] I.C. Vieira, K.O. Lupetti, F.-F. Orlando, Anal. Lett. 35 (2002) 2221.

[19] G. Marrazza, I. Chianella, M. Mascini, Anal. Chim. Acta 387 (1999) 297.

[20] W.-D. Zhang, H. Chen, Q.-M. Luo, Talanta 58 (2002) 529.

[21] D.J. Guo, H.-L. Li, Electrochem. Commun. 6 (2004) 999.

[22] J. Liu, W. Zhou, T. You, F. Li, E. Wang, S. Dong, Anal. Chem. 68 (1996) 3350.

[23] J. Wang, M.P. Chatrathi, B. Tian, R. Polsky, Electroanalysis 12 (2000) 691.

[24] D.K. Saha, K. Koga, K.-I. Ohshima, J. Phys.: Condens. Matter 4 (1992) 10093.

[25] G. Liu, T.P. St. Clair, D.W. Goodman, J. Phys. Chem. B 103 (1993) 8578.

[26] A.J. Dyakonov, Appl. Catal. B 45 (2003) 257.

[27] P.H. Espeel, G. De Peuter, M.C. Tielen, P.A. Jacobs, J. Phys. Chem. 98 (1994) 11588.

[28] O.M. Ilinitch, L.V. Nosova, V.V. Gorodetskii, V.P. Ivanov, S.N. Trukhan, E.N. Gribov, S.V. Bogdanov, F.P. Cuperus, J. Mol. Catal. A: Chem. 158 (2000) 237.

[29] J.A. Anderson, M. Fernández-García, G.L. Haller, J. Catal. 164 (1996) 477.
[30] L.Y. Leon, A. Carlos, M.A. Vannice, Appl. Catal. 69 (1991) 305.

[31] L. Lianos, Y. Debauge, J. Massardier, Y. Jugnet, J.C. Bertolini, Catal. Lett. 44 (1997) 211.

[32] F. Skoda, M.P. Astier, G.M. Pajonk, M. Primet, Catal. Lett. 29 (1994) 159.

[33] L.H. Bloxham, S. Haq, Y. Yugnet, J.C. Bertolini, R. Raval, J. Catal. 227 (2004) 33.

[34] J.-M. Zen, H.-H. Chung, A.S. Kumar, Analyst 125 (2000) 1633.

[35] J.-M. Zen, C.-T. Hsu, A.S. Kumar, H.-J. Lyuu, K.-Y. Lin, Analyst 129 (2004) 841.

[36] L.D. Burke, L.C. Nagle, J. Electroanal. Chem. 461 (1999) 52.

[37] C.-C. Hu, T.-C. Wen, Electrochim. Acta 40 (1995) 495.

[38] J. Ren, H. Zhang, Q. Ren, C. Xia, J. Wan, Z. Qin, J. Electroanal. Chem. 504 (2001) 59.

[39] J.-M. Zen, A.S. Kumar, J.-C. Chen, Anal. Chem. 73 (2001) 1169.

[40] S. Poulston, P.M. Parlett, P. Stone, M. Bowker, Surf. Int. Sci. 24 (1996) 811.

[41] S.Y. Lee, N. Mettlach, N. Nguyen, Y.M. Sun, J.M. White, Appl. Surf. Sci. 206 (2003) 102.

[42] J.A. Rodriguez, R.A. Campbell, D.W. Goodman, J. Phys. Chem. 94 (1996) 6936.

[43] G. Liu, T.P. St. Chair, D.W. Goodman, J. Phys. Chem. B 103 (1999) 8578.

[44] Y.Y. Liu, D. Hofmann, Anal. Chem. 45 (1973) 2270.

[45] Y.Y. Liu, I. Schmeltz, D. Hofmann, Anal. Chem. 46 (1974) 885.

[46] J.-W. Sue, A.S. Kumar, H.-H. Chung, J.-M. Zen, Electroanalysis, early view. 